\title{
Malignant atrophic papulosis
}

INSERM

\section{Source}

INSERM. (1999). Orphanet: an online rare disease and orphan drug data base. Malignant atrophic papulosis. ORPHA:679

Malignant atrophic papulosis (MAP) is a rare, chronic, thrombo-obliterative vasculopathy characterized by papular skin lesions with central porcelain-white atrophy and a surrounding teleang iectatic rim. Systemic lesions may affect the gastrointestinal tract and the central nervous system (CNS) and are potentially lethal. 